\title{
Analysis of Thyristor Controlled Series Capacitor Performance in Power Flow Control for High Voltage Transmission Lines
}

\author{
Dr. Han Su Yin \\ Professor \\ Department of Electrical Power Engineering, \\ Yangon Technological University \\ Yangon, Myanmar
}

\author{
Shwe Zan Aung \\ Project and System Design Engineer \\ Omega Integration PTE Ltd \\ Singapore
}

\begin{abstract}
In modern days due to the ever increasing in demand for electric power, the transmission lines are usually required to operate under full load condition and, consequently, there is a higher impact to the power flow in case the large interconnected transmission networks encounter faults due to many factors. Changing loads and atmospheric conditions are unpredictable factors. This paper purposes power flow control between parallel lines by using Thyristor Controlled Series Capacitor (TCSC). It is a series controller from the flexible AC Transmission System (FACTS) family. It consists of back to back Thyristor. By changing the firing angle of this back to back Thyristor it is possible to vary the reactance of the TCSC. In this paper this device is used to regulate the transmission line reactance in order to share power flow if any disturbance occurs during the transfer of electric power. This device can also work continuously by solving the errors in transmission lines. The systematic procedure for modeling and simulation are proposed by using MATLAB/ Simulink. The optimal location of TCSC device is considered for power flow control. The proposed approach is carried out on two area test system.
\end{abstract}

Keywords: TCSC, FACTS, Power Flow, MATLAB, Thyristor

\section{INTRODUCTION}

Today's modern interconnected power system is highly complex in nature. One of the most important requirements during the operation of the electric power system is the reliability and stability. [1] Transmission system is very important in Myanmar because the generation system locates far away from load center. Recent development in power electronic introduces the use of flexible AC transmission system (FACTS) controllers in power systems. FACTS controllers are capable of controlling the network condition in a very fast manner. Among them TCSC is one of the important members of FACTS family. It can have various roles in the operation and control of power systems, such as scheduling power flow; decreasing unsymmetrical components; reducing net loss; providing voltage support limiting short-circuit currents; mitigating sub-synchronous resonance (SSR); damping the power oscillation and enhancing transient stability as well as sharing power flow between parallel lines. The main purpose of this paper is to control the equivalent impedance of transmission lines to share power flow among parallel lines under disturbances. ${ }^{[3]}$ The placement of TCSC devices will be determined by using the load flow analysis i.e. Newton- Raphson method. ${ }^{[4]}$

The transmission system does not have the same power flow when there is a disturbance or increase in load demand or changes in system. This problem can be solved by using TCSC to regulate the power flow in AC transmission line. Power flow in Electrical system can be shared equally by adjusting reactance parameter of the transmission line. Figure 1 show a single line diagram of a simple transmission line with an inductive transmission reactance $\mathrm{X}_{\mathrm{L}}$, connecting to sending end voltage source $\mathrm{V}_{\mathrm{s}}$ and receiving end voltage source $\mathrm{V}_{\mathrm{r}}$, respectively.

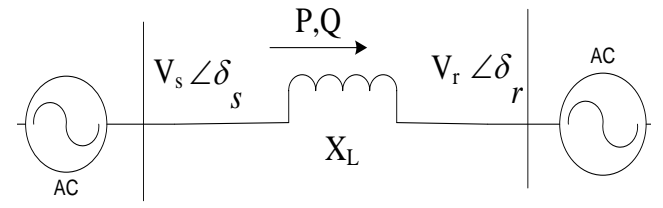

Figure 1. Two-Bus Transmission System ${ }^{[5]}$

The real power $(\mathrm{P})$ flow at the receiving end is shown in equation (1).

$$
\mathbf{P}=\frac{\mathrm{V}_{\mathrm{s}} \mathrm{V}_{\mathbf{r}}}{\mathrm{X}_{\mathrm{L}}} \sin \left(\delta_{\mathrm{s}}-\delta_{\mathrm{r}}\right)
$$

Where, $\mathrm{V}_{\mathrm{s}}$ and $\mathrm{V}_{\mathrm{r}}$ are the magnitude and $\delta_{\mathrm{s}}$ and $\delta_{\mathrm{r}}$ are the phase angles of the voltages, respectively. ${ }^{[5]}$

\section{THYRISTOR CONTROLLED SERIES CAPACITOR (TCSC)}

All Series Capacitors are installed in series with a transmission line. One of the significant devices from the group is a TCSC, which finds application in solving many problems in the power system. Its properties can increase the power lines transmission capacity, share power flow between the parallel lines and power flow control. TCSC is a FACT device available for application in AC line of voltage up to $500 \mathrm{kV} .{ }^{[1]}$ The capacity is inserted directly in series with the transmission line and the thyristor controlled inductor is mounted directly in parallel with the capacitor. ${ }^{[3]}$ 


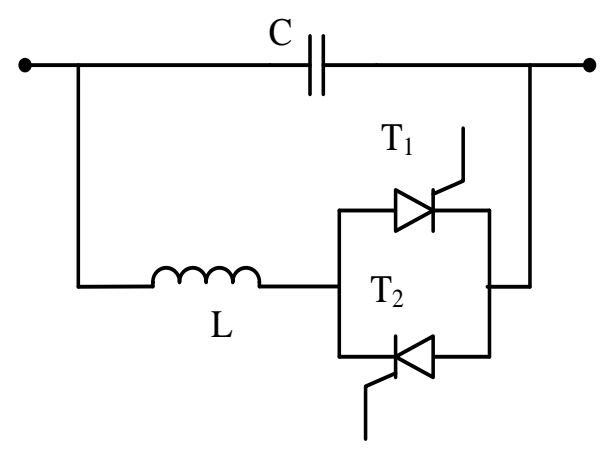

Figure 2. Simple Diagram of TCSC ${ }^{[3]}$

\subsection{Operation of the TCSC}

The value of the firing angle is required to be calculated for the operation of TCSC. But, this calculation involves an iterative process. One way to avoid these iterative processes is to use the alternative TCSC Variable Impedance Power Flow model presented in this section. The fundamental frequency equivalent reactance XTCSC of the TCSC module is: ${ }^{[4]}$

$$
\begin{aligned}
& \mathrm{X}_{\mathrm{TCSC}}=-\mathrm{X}_{\mathrm{C}}+\mathrm{C}_{1}\{2(\pi-\alpha)+\sin [2(\pi-\alpha)]\} \\
& -\mathrm{C}_{2} \cos ^{2}(\pi-\alpha)\{\omega \tan [\omega(\pi-\alpha)]-\tan (\pi-\alpha)\}
\end{aligned}
$$

Where,

$$
\begin{aligned}
& C_{2}=\frac{4 X_{L C}^{2}}{X_{L} \pi} \\
& C_{1}=\frac{X_{C} X_{L C}}{\pi} \\
& X_{L C}=\frac{X_{C} X_{L}}{X_{L}-X_{C}} \\
& \omega=\sqrt{\frac{X_{C}}{X_{L}}}
\end{aligned}
$$

\subsection{Modes of TCSC}

There are essentially three modes of TCSC operation. They are Bypassed Thyristor Mode, Blocked Thyristor Mode (Waiting Mode), Partially Conduction Thyristor (Vernier Mode). Furthermore, Vernier Mode has Capacitive and Inductive Vernier Mode. ${ }^{[5]}$

Mode I (Bypassed Mode): The thyristor is gated for 180 degrees. The susceptance of the reactor is greater than capacitor. Most of the line current passes through reactor and thyristor valves. For protection of capacitor against overvoltage, this mode is used. ${ }^{[2]}$

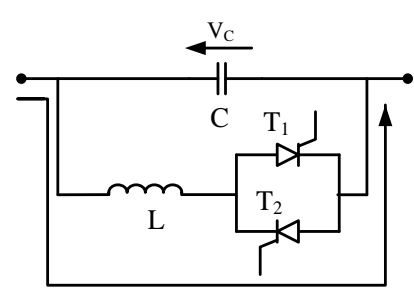

Figure 3. Bypassed Mode ${ }^{[5]}$
Mode II (Blocking Mode): No current pass through valves and gate pulses are blocked. The reactance of TCSC and fixed capacitor is similar.

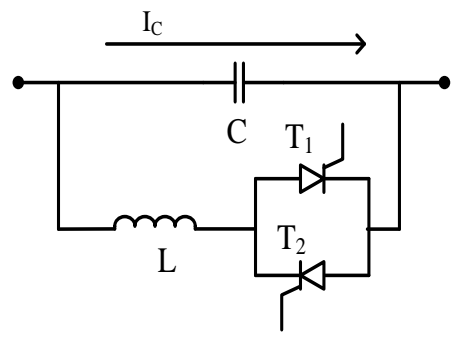

Figure 4. Blocking Mode ${ }^{[5]}$

Mode III (Vernier Mode): The Thyristor valves are operated by two gate pulses in the two regions, i.e. capacitive vernier region and inductive vernier region. ${ }^{[2]}$

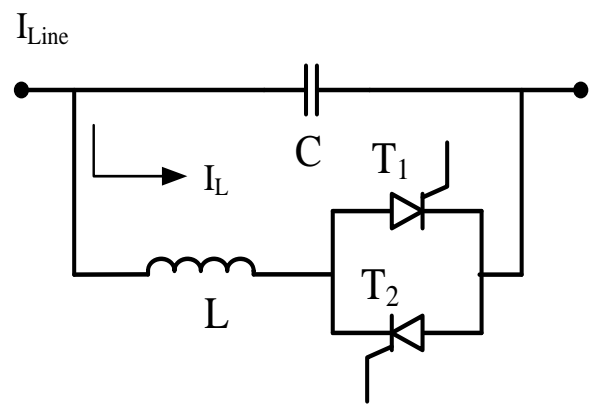

Figure 5. Inductive Mode ${ }^{[5]}$

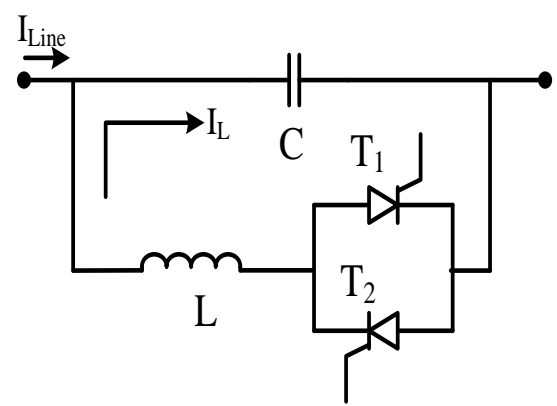

Figure 6. Capacitive Mode ${ }^{[5]}$

The natural characteristic of the series capacitor of compensated line cannot change by bypassing the series capacitor and high degree of compensation can cause sub synchronous oscillations. ${ }^{[2]}$

\section{CASE STUDY}

There are three transmission lines showing under study in Taungdwingyi substation. In this paper Taungdwingyi substation is sending end and Shwedaung substation is receiving end. Among them, $230 \mathrm{kV}$ single Shwedaung line, $230 \mathrm{kV}$ Shwedaung line 1 and $230 \mathrm{kV}$ Shwedaung line 2 are studied. The line length of $230 \mathrm{kV}$ Shwedaung line is 158.43 $\mathrm{km}$ and the line length of $230 \mathrm{kV}$ Shwedaung line $1 \& 2$ is $168.168 \mathrm{~km}$. The size of these cables is $605 \mathrm{MCM}$. This cable size can carry $773 \mathrm{~A}$. 


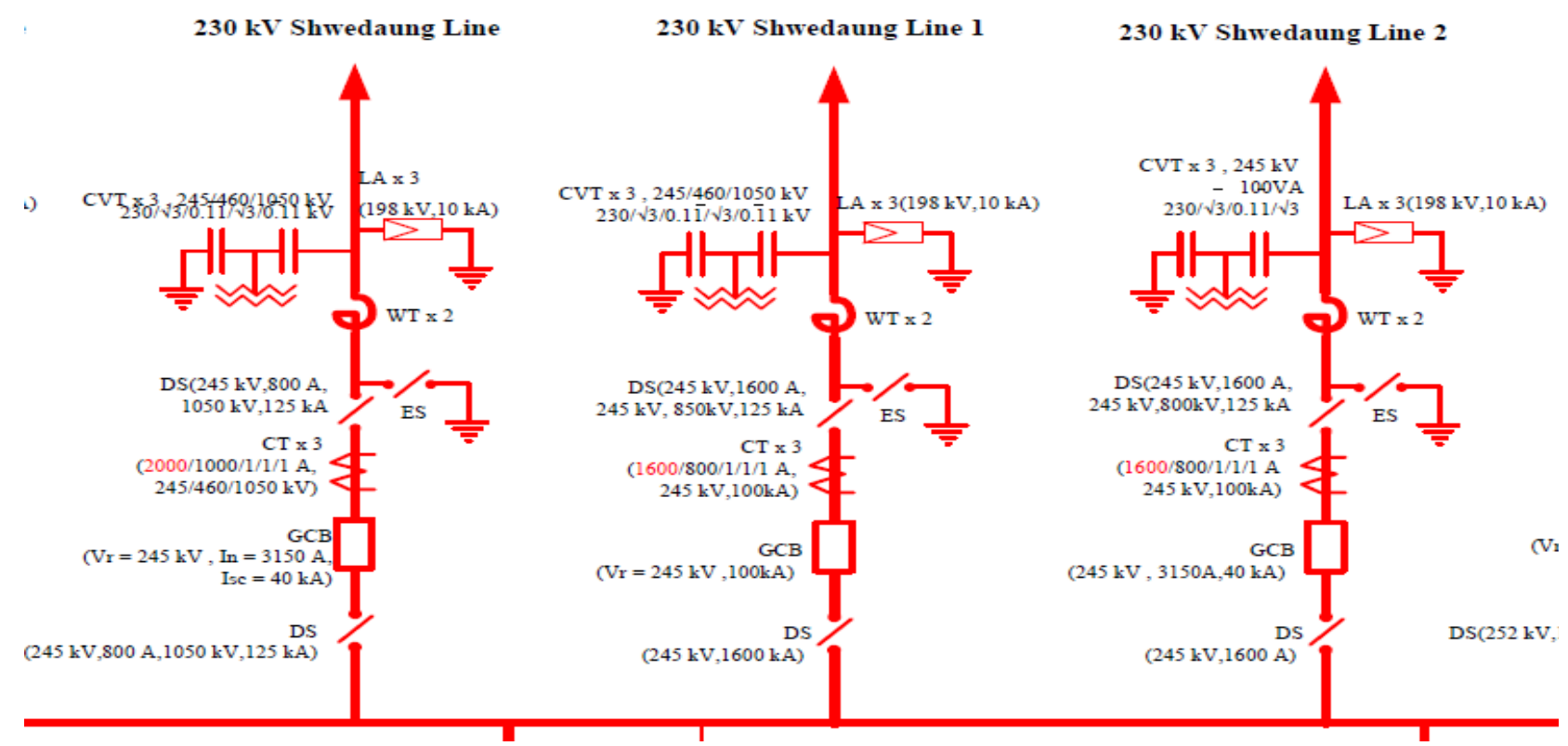

Figure 7. One Line diagram of Taungdwingyi Substation showing Transmission Lines under Study

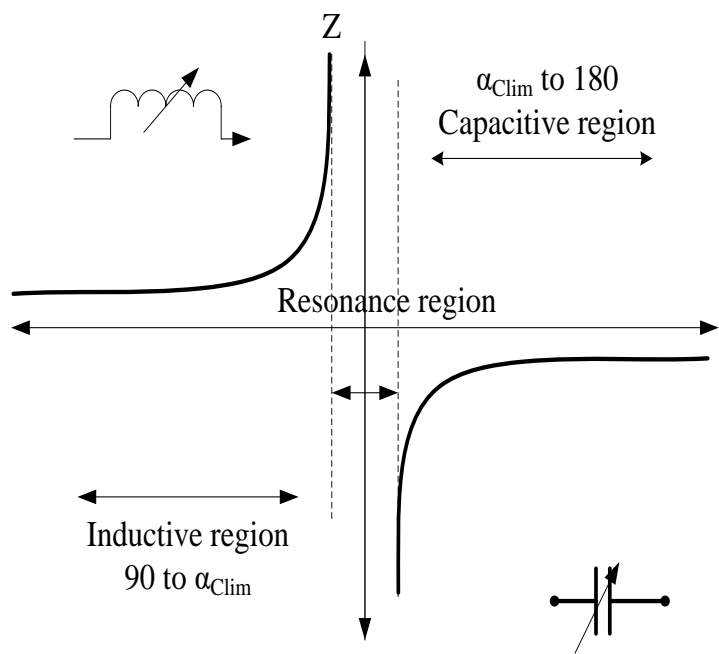

Figure 8. Impedance versus Firing Angle Characteristic of a TCSC ${ }^{[5]}$

\subsection{Data Calculation of Taungdwingyi- Shwedaung Old Line and the Existing System}

Table 1 shows data calculation of Taungdwingyi-Shwedaung old line and TCSC parameter. These data are required to calculate the rating and placement of TCSC. Figure 9 shows the existing system having both sending end and receiving end. These are connected with single old line and doubled new lines.

In proposed area there is unbalance power flow in parallel lines. The old line has higher power flow than new lines. But the power flows of new lines are balance. The purpose of this paper is to share the power flow between parallel lines. In order to share power flow, TCSC is used in proposed area. Figure 10 shows power flow in single old line and double new lines. Reactive power flow in single old line and double new lines is also shown in Figure 11. The magnitude of power in old line is 107.2 MW and the amount of power of new line 1 and 2 is $101.1 \mathrm{MW}$.

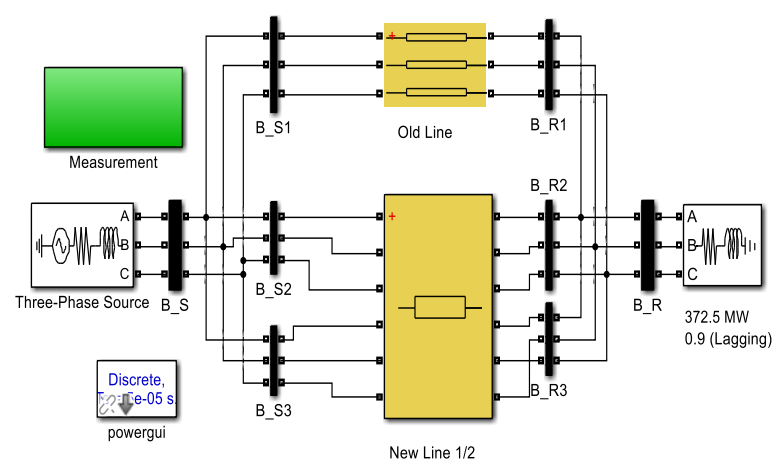

Figure 9. Simulink Model at Existing System

Table 1. Line Flow of Taungdwingyi-Shwedaung Transmission Lines Substation

\begin{tabular}{|c|c|c|c|c|}
\hline No. & Name & $\begin{array}{c}\text { Average } \\
\text { Power } \\
\text { (MW) }\end{array}$ & $\begin{array}{c}\text { Average } \\
\text { Maximum } \\
\text { Power (MW) }\end{array}$ & $\begin{array}{c}\text { Average } \\
\text { Minimum } \\
\text { Power (MW) }\end{array}$ \\
\hline 1 & $\begin{array}{c}\text { Old } \\
\text { Line }\end{array}$ & 123.188 & 188.95 & 34.224 \\
\hline 2 & $\begin{array}{c}\text { New } \\
\text { Line1 }\end{array}$ & 115.204 & 188.344 & 31.814 \\
\hline 3 & $\begin{array}{c}\text { New } \\
\text { Line 2 }\end{array}$ & 118.113 & 182.726 & 31.23 \\
\hline
\end{tabular}

Table 2. Data Calculation of Taungdwingyi-Shwedaung Transmission Line and TCSC Parameters

\begin{tabular}{|c|l|c|}
\hline No. & \multicolumn{1}{|c|}{ Name } & $\begin{array}{c}\text { Average Power } \\
\text { (MW) }\end{array}$ \\
\hline 1 & Line Reactance (XTCSC) in old line & $48.4 \Omega$ \\
\hline 2 & Capacitance reactance (XC) & $18.15 \Omega$ \\
\hline 3 & Inductance reactance (XL) & $72.6 \Omega$ \\
\hline 4 & Capacitance (C) & $1.75337 \times 10-4 \mathrm{~F}$ \\
\hline 5 & Inductance (L) & $0.23109 \mathrm{H}$ \\
\hline 6 & K (Compensation level) & $50 \%$ \\
\hline
\end{tabular}




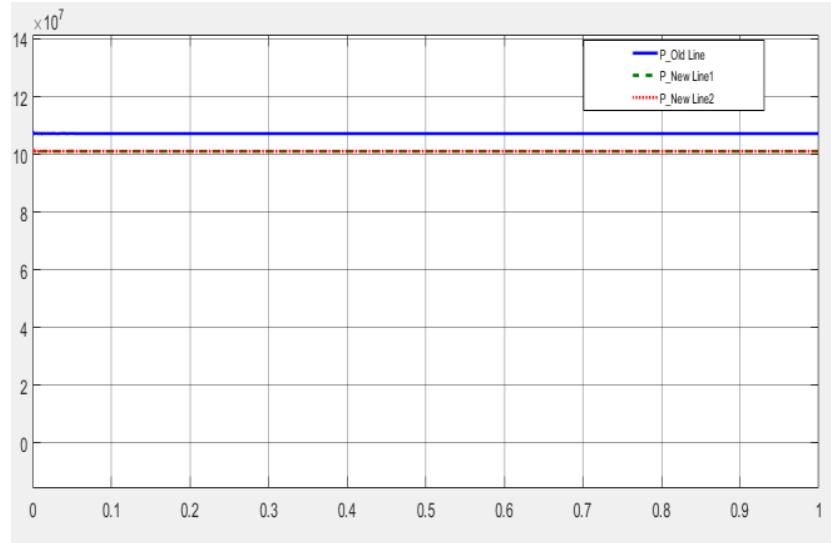

Figure 10. Power Flow Result of Existing System

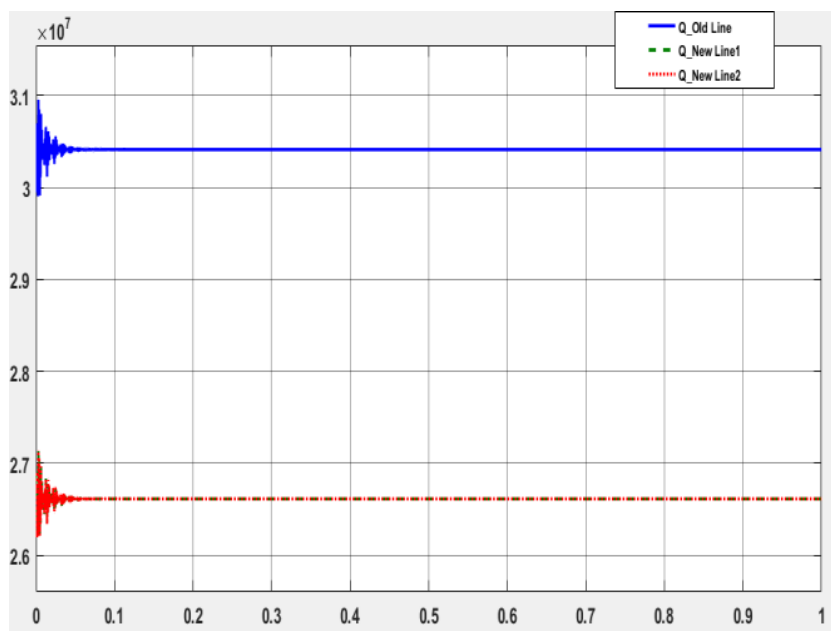

Figure 11. Reactive Power Flow in Existing System

\section{TEST SYSTEM SIMULATION MODEL OF TCSC USING MATLAB/ SIMULINK}

The source voltages of $230 \mathrm{kV}$ are connected by a $158.43 \mathrm{~km}$ transmission old line and $168.168 \mathrm{~km}$ double new lines. The loads in area having $372.5 \mathrm{~kW}$ are chosen so that the real power flows on the transmission line from Taungdwingyi to Shwetaung. The TCSC used for this model is a phasor model. ${ }^{[1]}$ Figure 12 shows Simulink model of TCSC in old line. To analyze the power control performance of TCSC under fault conditions, the fault is applied at the sending end of new line 2 as shown in Figure 12.

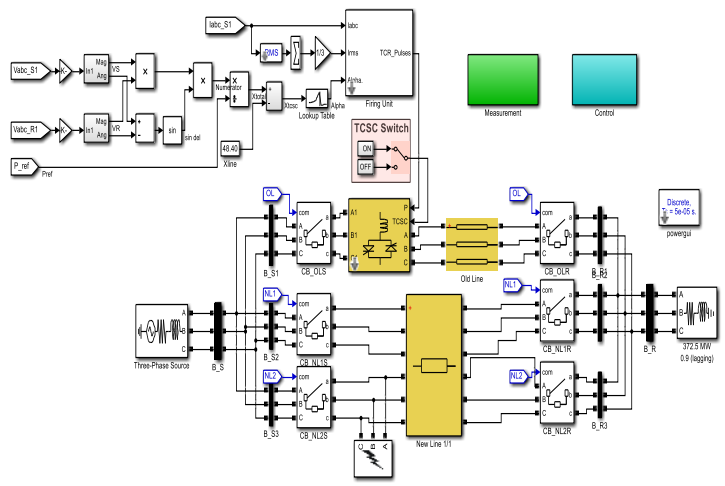

Figure 12. Simulink Model of TCSC in Old Line

\subsection{Control Operation of TCSC}

The TCSC may appear multi resonant points in 90 degrees to 180 degrees of $\alpha$. Nevertheless, only one resonant point, namely one capacitive range and inductive range is allowable. Multiple resonant points will reduce the operating range of the TCSC. It is good for operating $\omega$ less than 3 . Inductive region is from 90 degrees to 97 degrees. From 97.14 degrees to 107.9 degrees is resonant region and capacitive region is between 108 degrees and 160 degrees.

TCSC Controller Design: The TCSC controller consists two main operational blocks. They are an external and internal control. ${ }^{[7]}$

External Control: The external control may include different control loops depending on the control objectives which is accomplished either automatically with a PI controller or manually through direct operator intervention to regulate the transmitted power. The conventional PI controller attempts to minimize the power deviation $(\Delta \mathrm{P})$ which is difference of reference power $\left(\mathrm{P}_{\text {ref }}\right)$ signal and measured power $\left(\mathrm{P}_{\text {means }}\right)$ flowing through line and provides the impedance $\left(\mathrm{X}_{0}\right){ }^{\left[{ }^{[7]}\right.}$

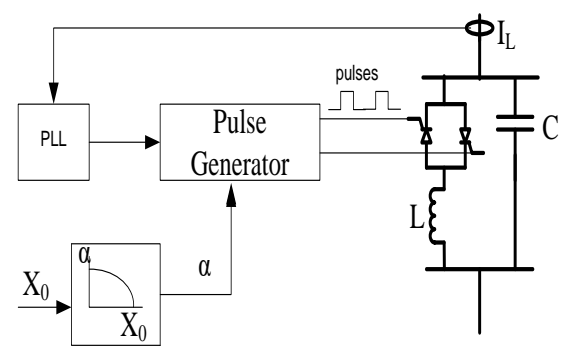

Figure 14. Internal Controller ${ }^{[8]}$

The internal control is shown in Figure 14. Then Figure 15, Figure 16, Figure 17 and Figure 18 are power flow and reactive power flow under fault condition without TCSC and with TCSC. By using TCSC, when fault occurs in new line 2 of sending end, the powers are shared by the remaining old line and new line 1 . When there is fault occurring at the receiving end, power cannot flow through all three lines.

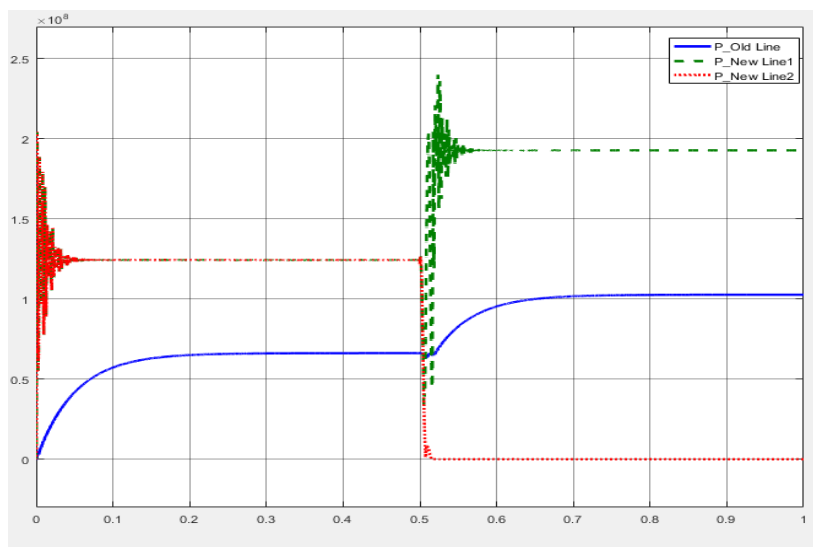

Figure 15. Real Power Flow under Fault Condition without TCSC

Figure 15 shows the real power flow under fault condition without TCSC. Power flows on the lines are not equal under normal condition as well as under fault condition. Power flow unbalance under fault is large. It is about 95.4 MW on old line and about $225 \mathrm{MW}$ on new line 1 . These unbalance in power will cause overload on new line 1 . The same condition can be observed for reactive power flow without TCSC as shown in Figure 16. 


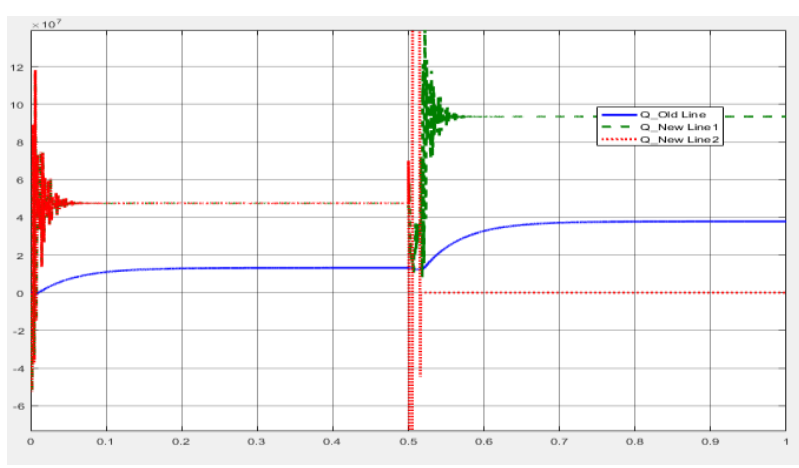

Figure 16. Reactive Power Flow under Fault Condition without TCSC

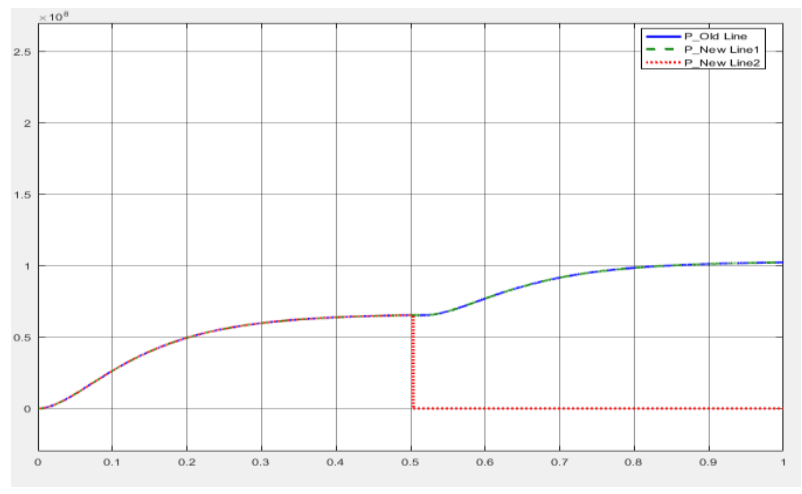

Figure 17. Power flow under Fault Condition with TCSC

To avoid overload on the line, the power flows on lines should be equal. Figure 17 and Figure 18 show the real and reactive power flow under fault condition with TCSC. As shown in these figures, the power flows on three lines are identical before fault condition. The active power is about $64.77 \mathrm{MW}$ and reactive power flow is about 11.76 MVAR on each line before fault. When the fault occurred at new line 2 , the active and reactive power flow on this line is drop to zero. Then the transferred power is served by the remaining two lines. With TCSC, the active powers on both remaining lines are equal with 102.3 MW and the reactive power flows are also identical with 11.89 MVAR. Thus the application of TCSC can control power flow under fault condition and overloading on one line is avoided.

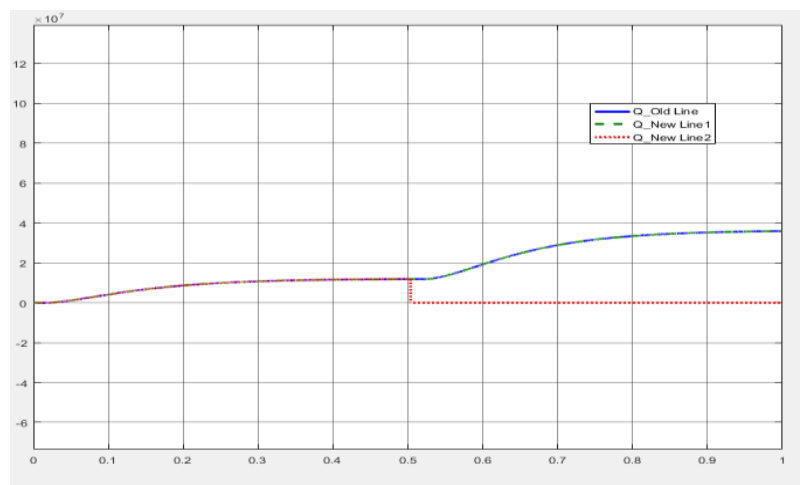

Figure 18. Reactive Power flow under Fault Condition with TCSC

\section{CONCLUSION}

In this paper, the analysis of power flow control between two ends of the transmission line to maintain power flow is studied. The study of TCSC device shows that this device controls the reactance of the system. The FACTS controller with its classification and performance of TCSC are included in this paper. To observe the power flow control performance by TCSC, the fault is applied at one of three line and the flows on the remaining two lines are observed. Without TCSC, the old line has higher power flow than new lines and real/reactive power unbalances are about 129.6 MW/ 55.64 MVAR. With TCSC, the power flows of remaining unfaulted lines are balanced and the real/reactive power unbalances are nearly zero. Therefore, the power flow can be shared equally under fault condition by using TCSC.

\section{ACKNOWLEDGEMENT}

I would like to express my sincere appreciation to Taungdwingyi and Shwedaung Substations for their supports on data collecting. I also would like to acknowledge special thanks to all of my teachers, my seniors and colleagues from Department of Electrical Power Engineering for their support and encouragement towards this paper.

\section{REFERENCES}

[1] Priyanka Kathal, Arti Bhandakkar, "Power Flow Control in Power System using FACT Device Thyristor Controlled Series Capacitor (TCSC)", Journal of Electrical and Electronics Engineering (IOSR-JEEE), Volume 7, Issue 6 (Sep-Oct-2013),72-83.

[2] Anita Kanwar, Rachit Saxena, "Behavior of TCSC in Transmission Line using MATLAB / Simulation", International Journal of Innovative Research In Electrical, Electronics, Instrumentation and Control Engineering, Volume 3, Issue 5, May 2015, 195-197.

[3] Ravi Kant Kumar, Sanjeet Kumar, Santan Kumar and K.S.S. Prasad, "Design of Thyristor controlled series capacitor for high voltage controllability and flexibility," Middle-East Journal of Scientific Research 20(1), 2014 134-138.

[4] Mr. A. Hema Sekhar, Dr. A. Lakshmi Devi, "Performance Improvement of Transmission System using TCSC with Firing Angle Control," Journal of Theoretical and Applied Information Technology, $15^{\text {th }}$ September 2016. Volume 91, 177-188.

[5] Priyanka Kathal, Arti Bhandakkar, "Power Flow Control in Power System using FACT Device Thyristor Controlled Series Capacitor (TCSC): A Review," International Journal of Science and Research (IJSR), India, 82-91, 388-395.

[6] S.Meikandasivam, Rajesh Kumar Nema, Shailendra Kumar Jain, "Behavioral Study of TCSC Device - A MATLAB/Simulink Implementation", International Journal Of Electrical and Computer Engineering, Volume 2, No. 9, 2008, 1958-1963.

[7] Xiaotian Wang, 2016. "Coordination of Power Flow Control by using FACTS Device and HVDC

Transmission System". ( A thesis submitted to Cardiff University in partial fulfillment of the requirements for the degree of MPhil, 2016) 